\title{
Observation of Cavity Interface and Mechanical Stress in Opaque Material by THz Wave
}

\author{
Tsuguhiro Takahashi \\ Central Research Institute of Electric Power Industry \\ Japan
}

\section{Introduction}

One of the recent topics of optical measurement techniques is the generation and utilization of the "Terahertz wave (THz wave)". In the long history of the research on electromagnetic waves, it remains as the last unrevealed area because its generation and detection techniques have not been sufficiently developed. In recent years, some useful and convenient devices have become commercially available, and much related research is being carried out. One important feature of $\mathrm{THz}$ wave is the high transmission probability through some opaque materials, many of which are dielectric materials through which a visible light beam cannot pass. Solid insulating materials are usually opaque dielectric materials, and it is difficult to measure their interior by conventional optical measurement techniques. If $\mathrm{THz}$ wave can pass through an insulating material sufficiently, the same measurement technique as with a visible light beam, already developed and practically applied, such as the technique of utilizing polarization, will become applicable. In this chapter, the research work on the introduction of $\mathrm{THz}$ wave techniques to the internal measurement of solid insulating materials is reviewed [1,2].

\section{Applicability of THz wave to internal measurement of solid insulating materials}

The dielectric strength of insulating materials generally increases in the order of gas < liquid $<$ solid, but from the viewpoints of the selfrecovery of insulation after discharge, the cooling method and so on, SF6 gas and insulating oil are generally adopted in high voltage electric power equipment. On the other hand, polyethylene is successfully utilized in high voltage XLPE cables with well controlled manufacturing techniques. In the research work on the "All Solid Insulated Substation" [3], high voltage moulded transformer, compact connector and bus system are being developed. Such equipment is expected to show high insulation performance, if there is no fault in the manufacturing process and it is operated with the monitoring of aging. Cost reduction will be realized by compactification and long time use, if solid insulating materials can be sufficiently utilized. Practical problems of solid insulating materials are, internal cavities (voids) occurrence, electrical and mechanical distortions and so on. In order to utilize solid insulating materials effectively, these faults should be monitored during production and operation, but there is no established non-destructive measurement method for opaque insulating materials. 
In order to obtain internal information from the outside, the detecting "probe" must be inserted. For a solid material, it is not possible to insert some objects, but sonic or electromagnetic waves can be utilized. These waves should have high transmission probability and sufficient interaction with the target to detect physical quantities. An example of the classifications of an electromagnetic waves is shown in Fig. 1.

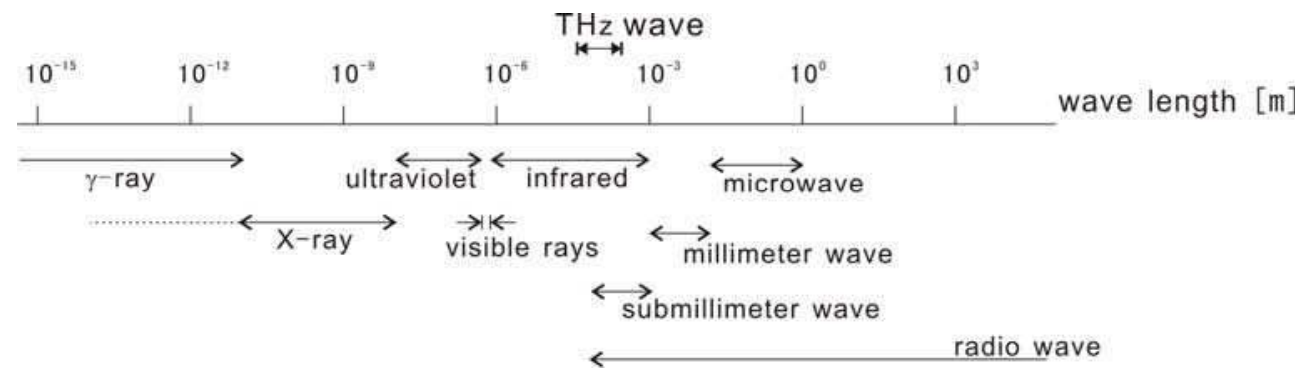

Fig. 1. Names and wave lengths of electromagnetic waves

"THz wave" means an electromagnetic wave with a "terahertz" frequency band. Generally, research work on electromagnetic waves of several100 $\mathrm{GHz}$ - several10 $\mathrm{THz}$ in frequency is being carried out recently. This frequency band has remained an "unrevealed area", but because of the recent development of several related techniques, such as the femtosecond laser, the generation and detection techniques of $\mathrm{THz}$ wave have been developed (Table 1 and Table 2), and several related applications are being examined. $\mathrm{THz}$ wave techniques are expected to be applied in a wide range of areas in the future.

\subsection{Transmission probability of THz wave for solid insulating materials}

Most solid insulating materials are opaque dielectric materials. "Opaque" means, visible light of about $400 \mathrm{~nm}-750 \mathrm{~nm}$ in wavelength and electro magnetic waves of around this band cannot be sufficiently transmitted. It is said that electromagnetic waves of longer wavelengths (far red) can be transmitted, and it is known that microwaves and millimeter waves, which have much longer wave lengths, can also be transmitted. In order to utilize $\mathrm{THz}$ waves for transmission measurement of solid insulating materials, it should be clarified, which frequency is suitable for target materials. But there is not yet a systematic database of such data.

Examples of measurement results of transmission probability for PE (polyethylene), Epoxy, silicone rubber, and EPDM (ethylene propylene diene Monomer) rubber, which are typical insulating materials, are shown in Fig. 2, 3, 4 and 5. Except for PE, there are large and almost flat absorptions for the indicated frequency range.

Other transmission probability measurements for several kinds of solid materials have been made, as shown in Fig. 6 as an example ${ }^{1}$. It was obtained with the $\mathrm{BWO}^{2}$ spectroscope (Fig. 7), which is commercially available. In Fig. 6, adjacent points have been averaged, but there

1 These characteristics are those of author's samples. There is a possibility the same material with other filler and manufacturing process will show other characteristics.

2 Back-ward Wave Oscillator Tube; it generates single frequency electromagnetic waves, which can be adjusted in the range of millimeter wave to sub-millimeter waves by changing the applied voltage. The changeable range depends on the model number of the tube. 
still remains oscillation, which is called the "etalon effect", which is decided by the thickness of samples $(5 \mathrm{~mm})$ and frequency. According to this data, the transmission probability of $\mathrm{THz}$ waves is not high for many solid materials. From the next section, actual measurement made for polyethylene, through which $\mathrm{THz}$ waves can transmit well, are described, but the same measurement can be applied for other materials with lower frequency waves (, in such a case, the spatial resolution of measurement should be worse).

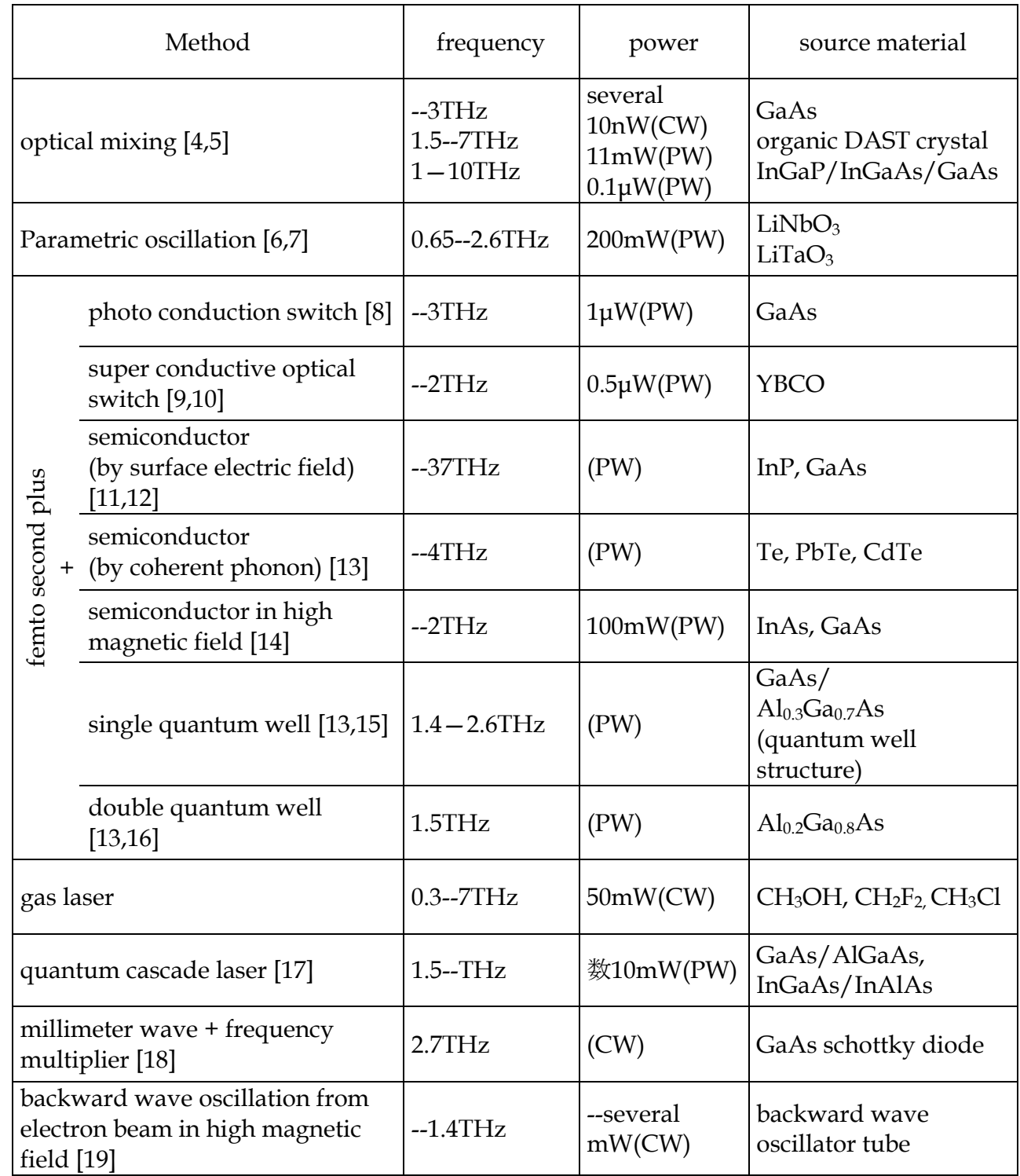

Table 1. Generation methods of THz wave (CW: continuous wave, PW: pulsed wave) 


\begin{tabular}{|l|l|}
\hline \multicolumn{1}{|c|}{ method } & \multicolumn{1}{c|}{ notes } \\
\hline $\begin{array}{l}\text { photo conduction switch } \\
{[13,16]}\end{array}$ & $\begin{array}{l}\text { The same switch as in the generation method is utilized. } \\
\text { Frequency spectrum is obtained from a waveform in the time } \\
\text { domain by Fourier transform. }\end{array}$ \\
\hline thermal absorbtion & $\begin{array}{l}\text { Temperature change of materials (gas cell) absorbing THz } \\
\text { wave is detected (, applicable for wide frequency range). }\end{array}$ \\
\hline EO sampling [13,16] & $\begin{array}{l}\text { THz wave intensity is converted to visible light beam } \\
\text { intensity by the Pockels effect. Imaging with a CCD camera is } \\
\text { realized. }\end{array}$ \\
\hline photon counting [20] & $\begin{array}{l}\text { Single electron transistor of quantum dot structure is utilized. } \\
\text { Intensity is measured directly as numbers of photons. }\end{array}$ \\
\hline $\begin{array}{l}\text { Superconductive tunnel } \\
\text { junction device [21] }\end{array}$ & $\begin{array}{l}\text { Photon-assisted tunneling effect is detected. There is the } \\
\text { possibility of being arrayed. }\end{array}$ \\
\hline
\end{tabular}

Table 2. Detection methods of $\mathrm{THz}$ wave

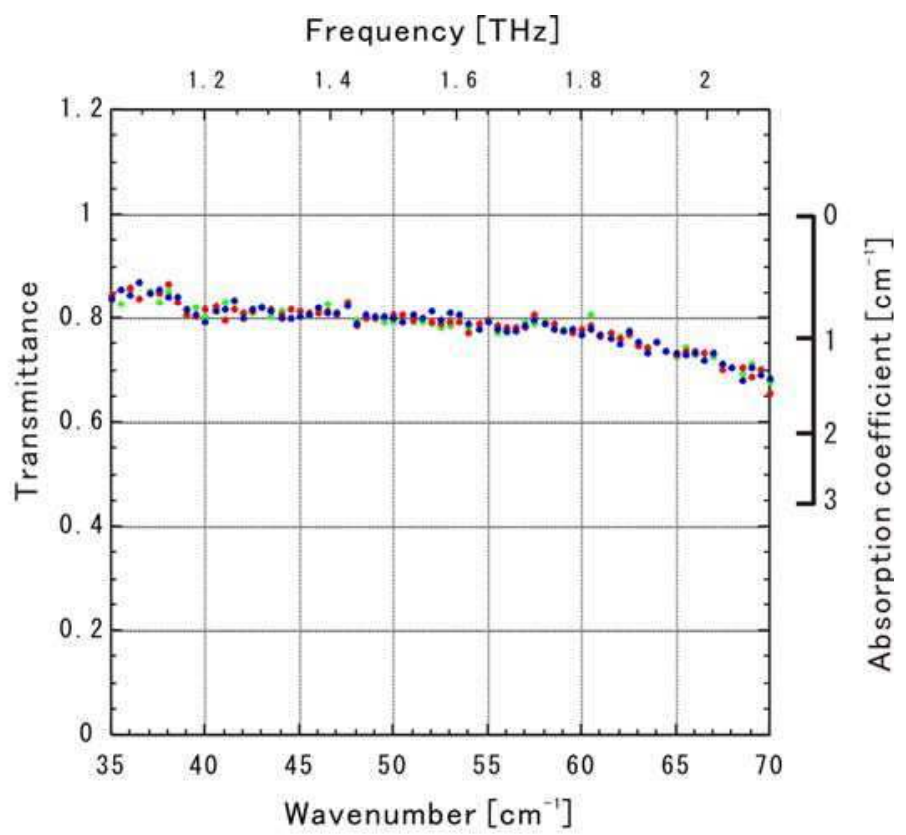

Fig. 2. Transmission probability measurement for PE (thickness: $2.7 \mathrm{~mm}$; dot colours represent measurement ID numbers) 


\section{Frequency $[\mathrm{THz}]$}

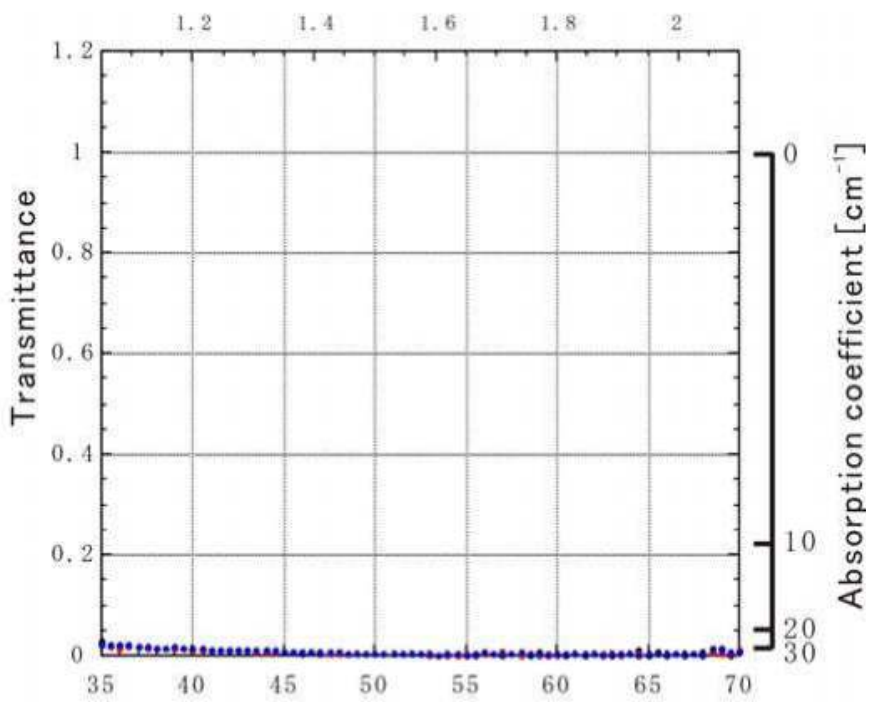

Wavenumber $\left[\mathrm{cm}^{-1}\right]$

Fig. 3. Transmission probability measurement for Epoxy (thickness: 1.5mm)

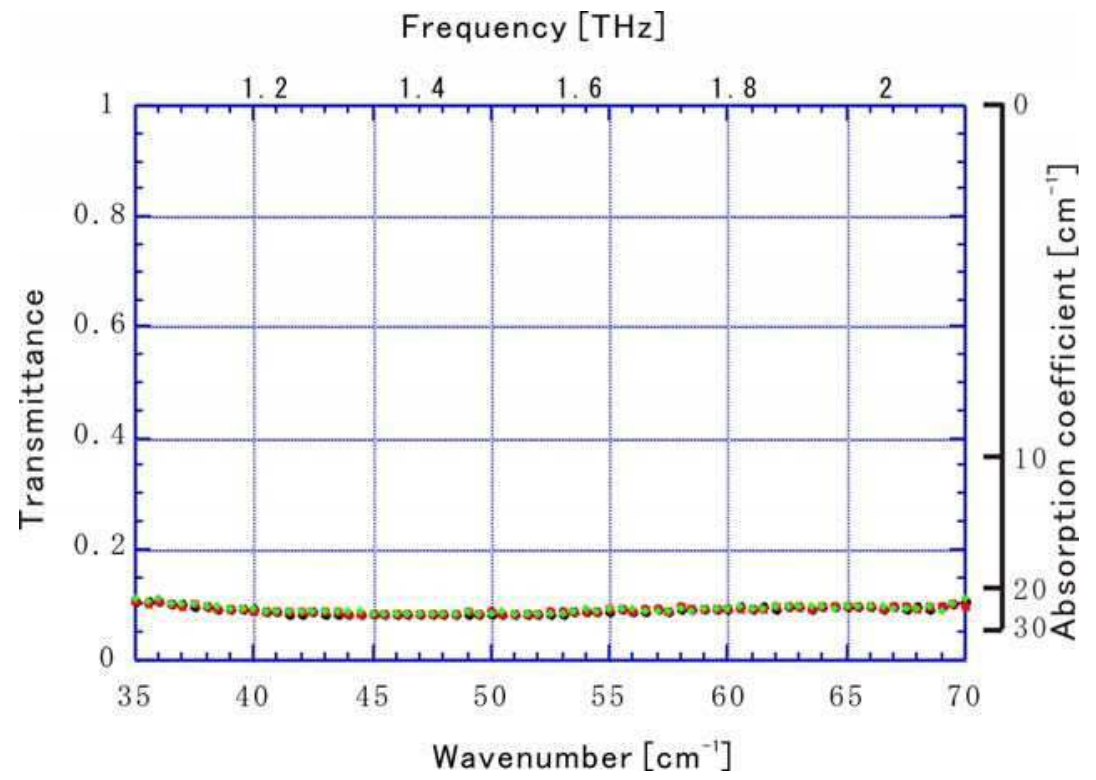

Fig. 4. Transmission probability measurement for silicone rubber (thickness: 1mm) 


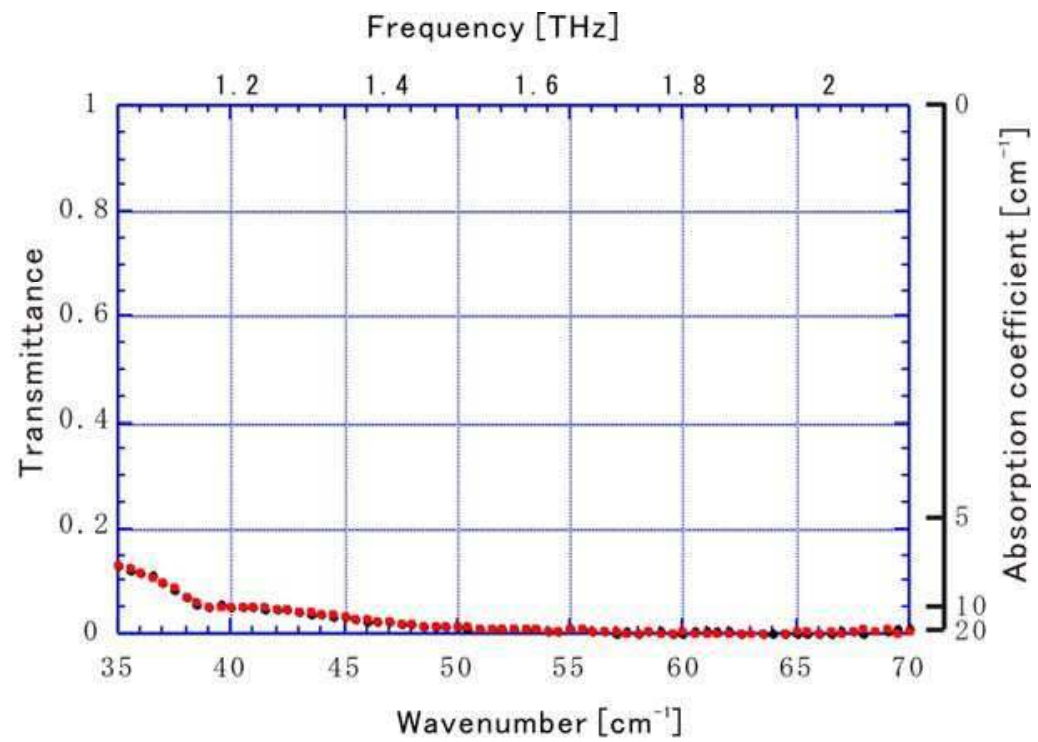

Fig. 5. Transmission probability measurement for EPDM rubber (thickness: 3mm)

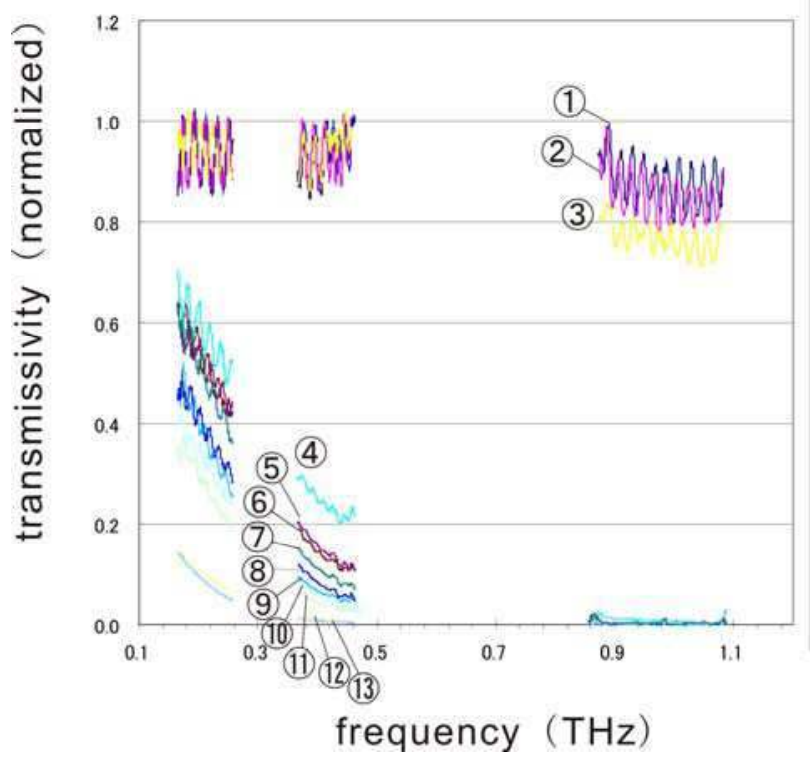

(1)polyethylene (2)polypropylene (3)PTFE (4) polycarbonate (5)PMMA

(6) $A B S$ (7) $P V C$ 8)nylon (9)PET (10)epoxy resin (11)urethane rubber (12) phenol resin (13)silicone rubber

Fig. 6. Transmission probability of solid materials 


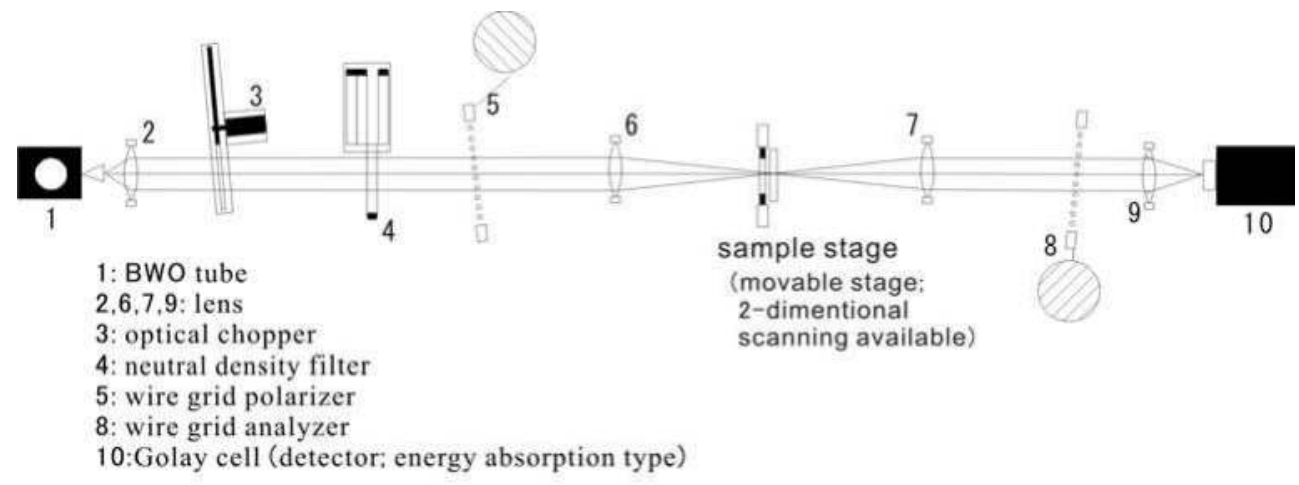

Fig. 7. Schematic of BWO experimental setup

\subsection{Possibility of internal physical quantity measurement of solid insulating materials} $<$ Cavity> For an internal cavity of solid materials, such as a void or a crack, all transmittable electromagnetic waves can be applied ${ }^{3}$. The key point is spatial resolution, which is decided by the wave length. By considering both its spatial resolution and transmission probability, a suitable wave length should be selected. Other than electromagnetic waves, ultra sonic waves are also applicable for elastic interfaces. It is said that the spatial resolution of ultra sonic methods reaches about $10 \mu \mathrm{m}$.

<Electric field> When electric field is applied to a material, an electron cloud of the constituent atoms is deformed, and as a consequence, its polarization, that is, dielectric constant (, or refractive index), changes. Among such phenomenon, the electro-optical Kerr effect (quadratic electro-optical effect) exists in all materials (, its quantity depends on the material $)^{4}$. Therefore, there is a possibility that the applied electric field can be detected through a change in the refractive index. Moreover, Maxwell stress is expected to occur with the application of electric field, and the refractive index also changes through the photoelastic effect. If a light beam is transmitted to the material, such a change of the refractive index is converted to a detectable polarization change of the incident light beam. The electric field in a solid material is expected to be detected by utilizing the polarized light beam (electromagnetic wave) as the detecting "probe". Its wave length (frequency) should be selected considering its transmission probability.

<Mechanical stress> When mechanical stress is applied to a material, its dielectric constant (refractive index) changes owing to the photoelastic effect. Therefore, similarly to the electric field, it is expected to be detected by utilizing a polarized light beam (electro magnetic wave). Such measurement is already practically utilized for transparent plastic material, such as poly methyl methacrylate, using a visible laser beam.

$<$ Thermal strain> When there is thermal strain in a material, such as an abnormal localized temperature rise in a solid insulating material, the distribution of the dielectric constant

\footnotetext{
${ }^{3}$ Electromagnetic waves of very short wave length (high energy), such as X-rays, should be handled with care as they may influence the target materials.

${ }^{4}$ Pockels effect (linear electro-optical effect) exists in only crystalline materials without centrosymmetry. Generally, cubic and higher electro-optical effects are said to be very small.
} 
changes because of the photoelastic effect, similarly to mechanical stress above mentioned. Therefore, a polarized light beam (electro magnetic wave) is expected to function as a detecting "probe", as for electric field and mechanical stress.

From the viewpoints of transmission probability and the possibility of an internal physical quantity in solid materials, as described, $\mathrm{THz}$ wave is expected to be a suitable detecting "probe" for insulating materials, when a suitable frequency is selected. The internal measurement technique using a visible light beam has already been utilized for transparent materials. This technique tends to be regarded for only transparent materials, but here, "transparent" means the "probe" light beam can be transmitted with sufficient probability. Therefore, by selecting a suitable frequency, the applicable areas of the internal measurement technique can be widely expanded.

\section{Study of internal measurement for a solid insulating material}

By utilizing the measurement system in Fig. 7, internal measurement for polyethylene has been examined.

\subsection{Detection of cavity interface}

One of the most frequent abnormal features is a cavity, such as a void or a crack. It is expected that the transmission intensity of the "probe" light beam differs between the normal part and the cavity, but there is a possibility the difference is insufficient from the viewpoint of the $\mathrm{S} / \mathrm{N}$ ratio. On the other hand, if there is a cavity, there must be an interface at which refraction occurs and light beam intensity changes. As a simple example, a polyethylene plate ( $5 \mathrm{~mm}$ thick) with holes $(10 \mathrm{~mm}$ and $8 \mathrm{~mm}$ in diameter) has been measured (2-dimensional scanning) with $\mathrm{THz}$ wave $(1.3 \mathrm{THz})$. The results are shown in Fig. 8. The light beam intensity at the hole is the highest, and a decrease in the light beam intensity is also prominent. This decrease is caused by refraction at the interface ${ }^{5}$. This result suggests that even if the transmission probability difference is not sufficiently large between the solid material and the cavity (normally, air), its interface should be clearly distinguishable. Another measurement example with a smaller hole $(1.5 \mathrm{~mm})$ is shown in Fig. 9. There is an area of light beam intensity decrease, which should depend on the thickness of the sample; therefore there is no area of light intensity increase in this case.

In these results, detected shapes of the cavity interface are deformed. This means that the measurement does not have high spatial resolution. From the viewpoint of cavity (void and crack) detection in a solid insulating material (detection of abnormal condition), there should be sufficient worth in establishing its existence or nonexistence, without an accurate shape measurement.

\subsection{Detection of mechanical stress}

In order to examine the measurement technique for mechanical stress in a solid material, a polyethylene sample ( $5 \mathrm{~mm}$ thick) pinched by a metal clamp has been measured using a 1.0

\footnotetext{
5 The light beam is condensed by lens. The refraction occurs according to relation between cavity interface angle and light beam direction. It is supposed, decreases of the light beam intensity at right and left side of holes in Fig. 4 differs according to the this relation.
} 
$\mathrm{THz}$ light beam. One measurement example is shown in Fig. 10. Fig. 10(a) is a simple scanned image of the transmission light beam intensity, and Fig. 10(b) was obtained with a polarizer and an analyzer placed form a cross-Nicol system. Fig. 10(a) shows the difference in the transmission probabilities of each part. In Fig. 10(b), the incident $\mathrm{THz}$ wave is linearly polarized by a polarizer with a tilted angle 45 degrees to the vertical direction, and the output $\mathrm{THz}$ wave transmitted from the sample is passed through an analyzer with a transmission direction tilted at an angle of 90 degrees to the polarizer. Therefore, Fig. 10(b) shows the polarization change of the transmitting $\mathrm{THz}$ wave in the sample. At the region of air and the polyethylene part with no mechanical stress, there is no polarization change and the detected signal intensity is very low. On the other hand, at the mechanically stressed polyethylene part, there occurs anisotropy of the dielectric constant because of the photoelastic effect, and the polarization of the transmitting $\mathrm{THz}$ wave changes from linear to elliptic. The elliptically polarized $\mathrm{THz}$ wave can be partially transmitted through the analyzer. Therefore, only the mechanically stressed polyethylene part is detected 6 .

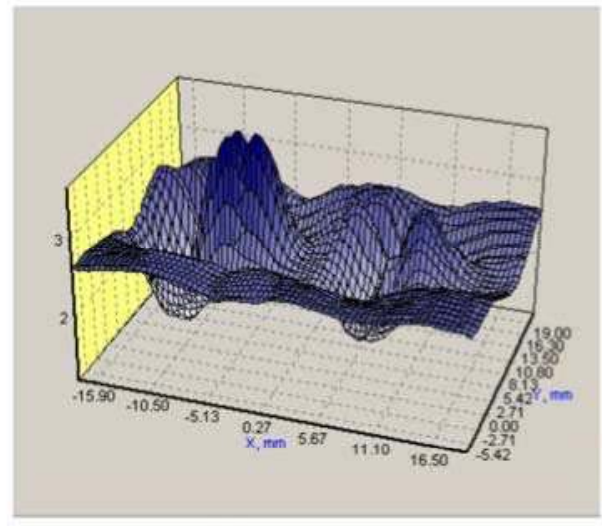

(a) 3D image

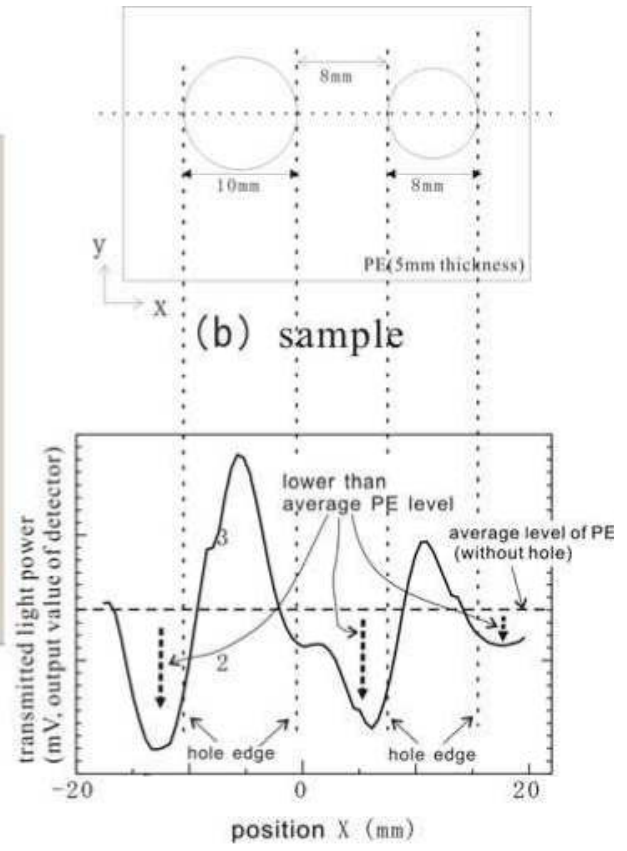

(c) scan result along $\mathrm{X}$-axis on dotted line in Fig (b)

Fig. 8. Result of scanning perforated PE panel

(scanning step: $0.54 \mathrm{~mm}$, scanning area: $37.3 \times 28.2 \mathrm{~mm}$ )

${ }^{6}$ With this cross-Nicol configuration, mechanical stress along horizontal direction in Fig.6(b) is detected. 


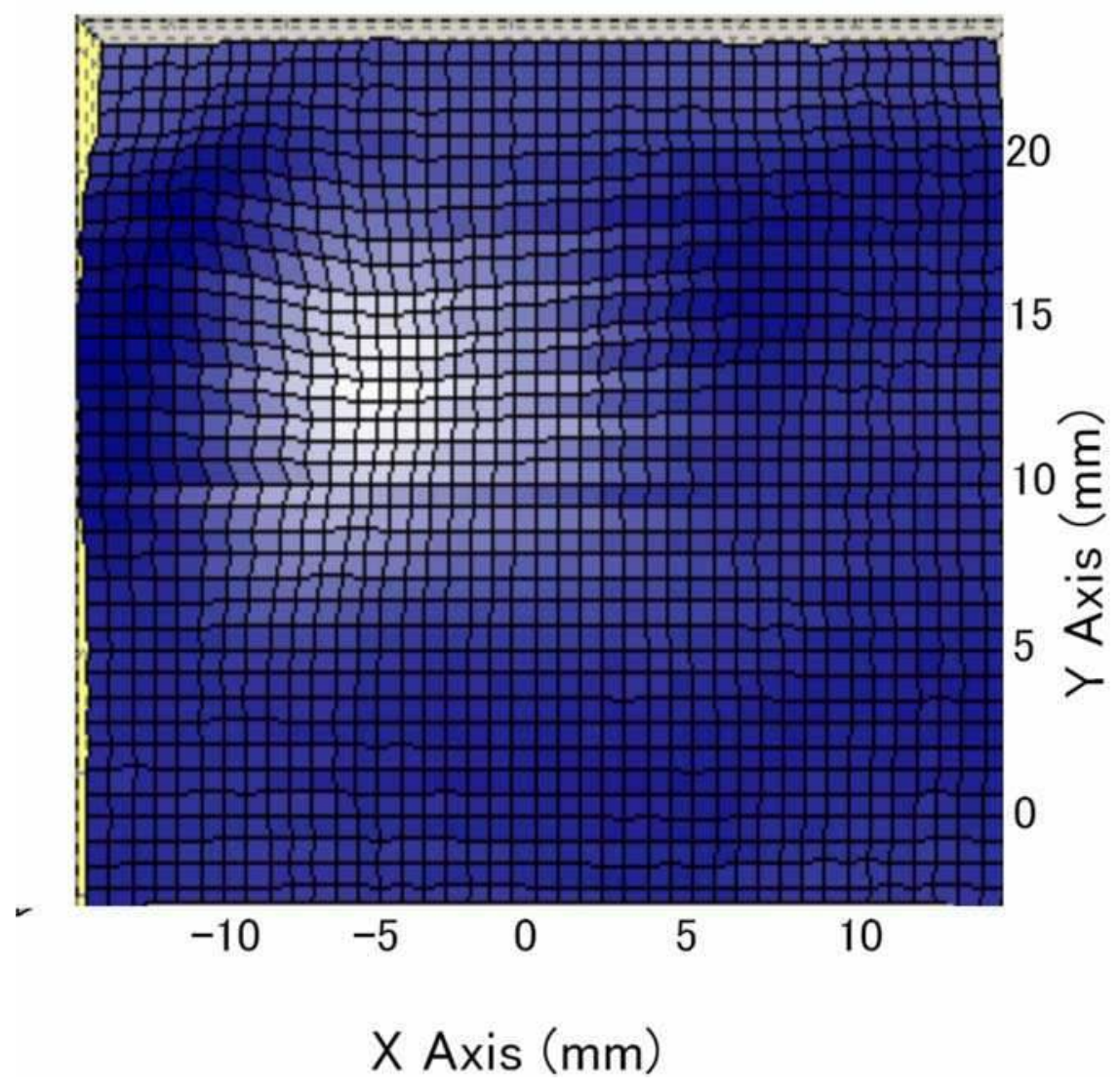

Fig. 9. Scanning image of PE panel with $1.5 \mathrm{~mm}$ hole (scanning step: $0.54 \mathrm{~mm}$, scanning area: $22.1 \times 21.1 \mathrm{~mm}$ )

When two orthogonally crossed coordinates and their normal stresses $\sigma 1$ and $\sigma 2$ are considered, the photoelestic effect is expressed by phase difference $\theta$ between two electric field components of the incident light beam along those coordinates as

$$
\theta=\frac{2 \pi \cdot h}{\lambda} \cdot C\left(\sigma_{1}-\sigma_{2}\right)
$$

where $\lambda$ is the wave length of the incident light beam, $h$ is the thickness of the sample, $C$ is the photoelastic constant. A phase difference such as that in Eq. (1) appears in materials with dielectric anisotropy. It can be detected by the "probe" light beam, as shown in Fig. 11. The dielectric anisotropy (refractive index anisotropy) affects the linearly polarized incident light beam, and the polarization of the output light beam becomes elliptical, the ellipticity of which is governed by the phase difference $\theta$. Generally a polarizer is utilized to make the polarization of the incident light beam linear, and an analyzer (, which is the same optical parts as a polarizer) is utilized to detect the ellipticity of the output light beam. As in the 
experiment corresponding to Fig. 10, when a mechanically stressed sample is set in a crossNicol system and the direction of normal stresses are set to the angle of 45 degrees to the transmitting direction of the polarizer and analyzer, the output light beam intensity from the analyzer $I$ is expressed as

$$
I=\frac{I_{0}}{2}\left\{1+\cos \left(\Delta \theta+\theta_{0}\right)\right\}
$$

where $I_{0}$ is the incident light intensity, and $\theta_{0}$ is the phase difference cased by the natural birefringence (, birefringence when $\sigma 1=\sigma 2$ ). The relationship between $I$ and $\theta$ is shown in Fig.12.

(a) without polarizer/analyzer

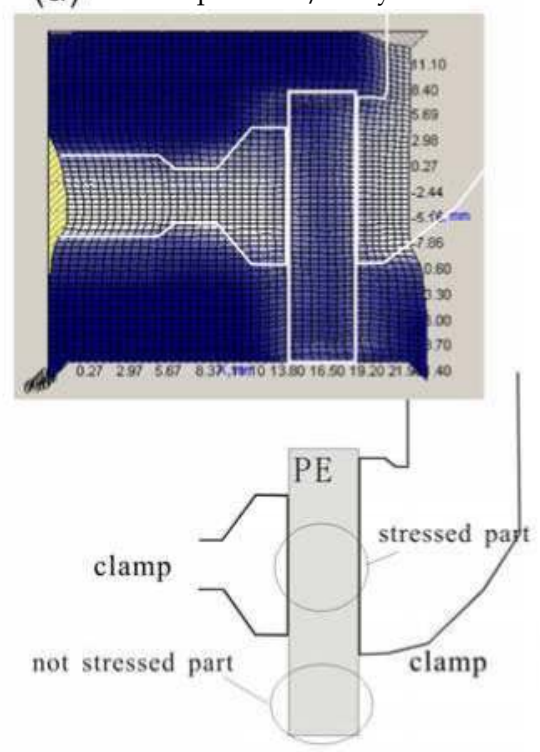

(b) polarizer $\perp$ analyzer
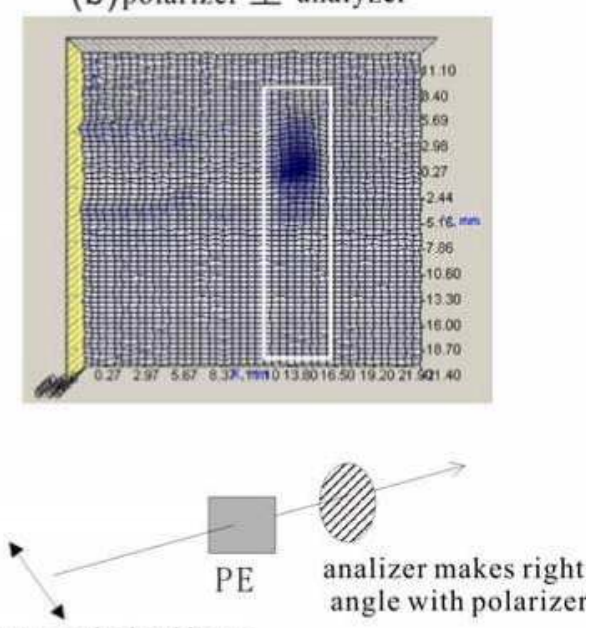

lineary polarised beam, tilted at 45 degrees by polarizr

Fig. 10. Scanning result of stressed PE panel

(detected stress direction: horizontal, scanning step: $0.54 \mathrm{~mm}$, scanning area: $23.2 \times 33.1 \mathrm{~mm}$ )

In order to confirm the positive relationship between applied mechanical stress and the difference in the refractive index, and to estimate the photoelastic constant of PE in the $\mathrm{THz}$ frequency range, the output $\mathrm{THz}$ wave strength from the analyzer has been measured by changing the applied mechanical stress. The stress was applied with a hydraulic jack, which was replaced with the sample stage in Fig. 7. The transmitted $\mathrm{THz}$ wave was $1.0 \mathrm{THz}$ in frequency, and the dimensions of the measured PE sample block were $70.4 \mathrm{~mm}$ in width, $30.5 \mathrm{~mm}$ in thickness (direction of mechanical stress application) and $30.9 \mathrm{~mm}$ in length (direction of $\mathrm{THz}$ wave transmission). The area of applying mechanical stress with the hydraulic jack was $70.4 \mathrm{~mm} \times 30.9 \mathrm{~mm}$. Under these conditions, 
the relationship between the applied mechanical stress and the phase difference $\theta$ in Eq. (1) was obtained, as shown in Fig. 13. In this measurement, very large stress was applied to the PE sample; therefore, some distortion was observed ${ }^{7}$. By measuring the sample size during this experiment, the relationship between applied mechanical stress and distortion was obtained, as shown in Fig. 14. The range in which mechanical stress is almost proportional to distortion can be regarded as the elastic region, and when stress is larger than the compressive yield strength of $\mathrm{PE}$, it can be said to be the plastic region and the distortion increases rapidly8. In Fig. 13, a linear approximation was made in the elastic region, and the photoelastic constant under these experimental conditions was estimated.

$$
C=4 \times 10^{-11}
$$

The estimation of the photoelastic constant in this frequency range seems to be unique.

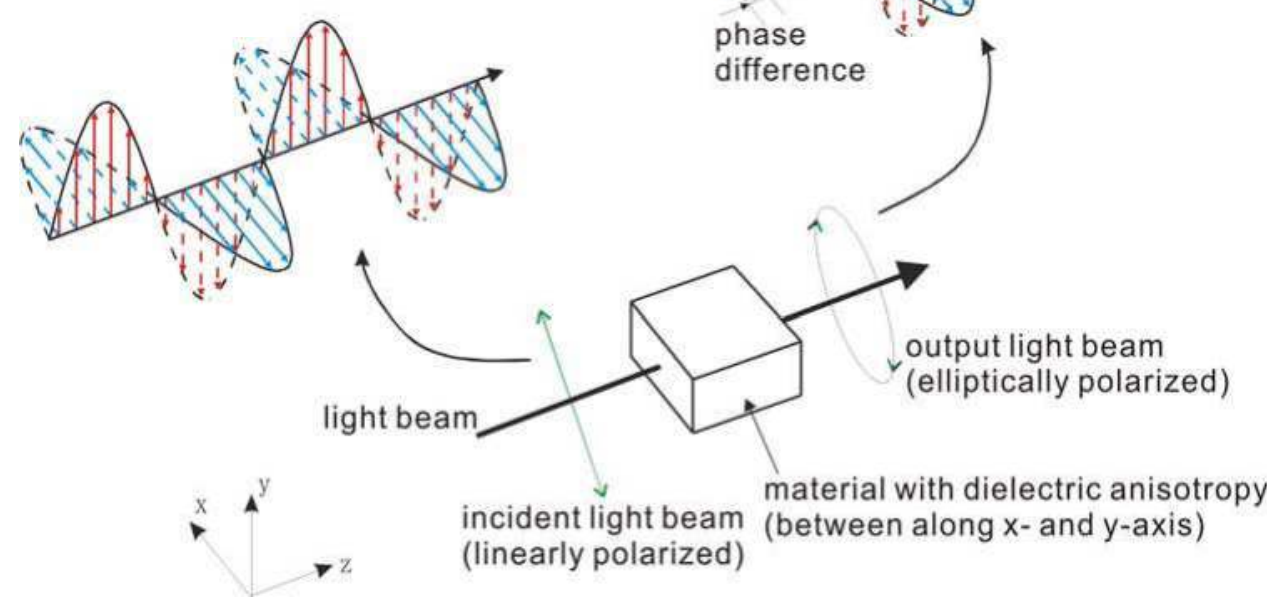

Fig. 11. Polarization change of "probe" light beam in material with dielectric anisotropy

\footnotetext{
7 The distortion of PE changed gradually after mechanical stress was applied. In this experiment, values of applied mechanical stress were recorded after the change was almost saturated (, about $30-60$ minutes after), from the stress value indicator of the hydraulic jack.

8 In this experiment, the compressive yield strength was obtained to be about $18-23 \mathrm{MPa}$, which is in agreement with some references (e.g., The Society of Polymer Science Japan, "Polymer Data Handbook" (1986)).
} 


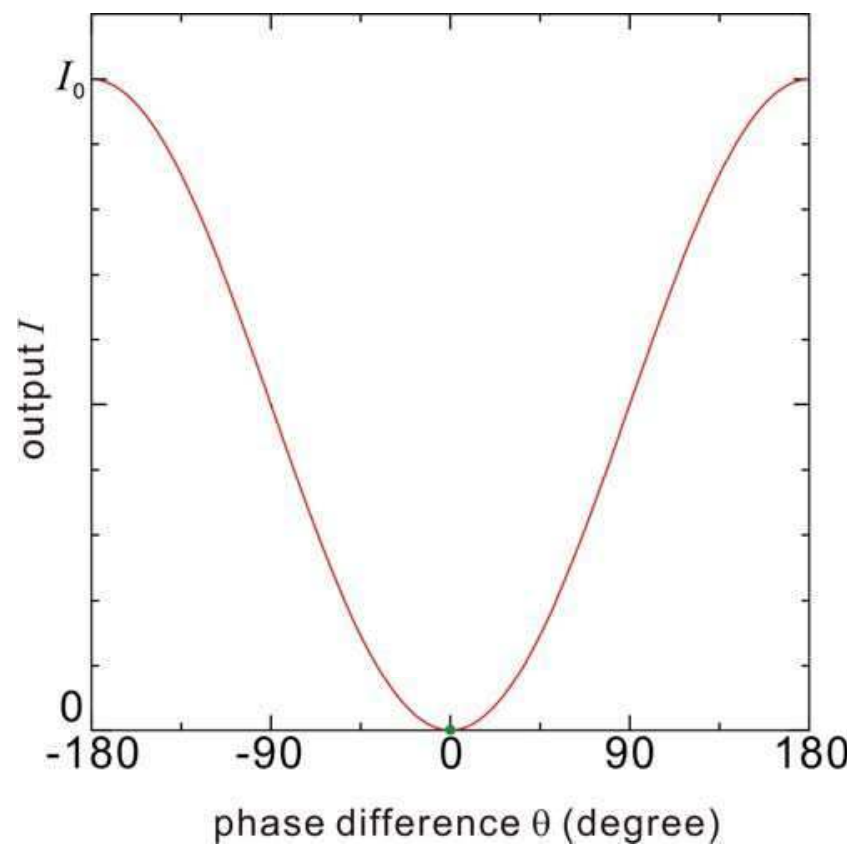

Fig. 12. Relationship between output light intensity from analyzer and phase difference $\theta$

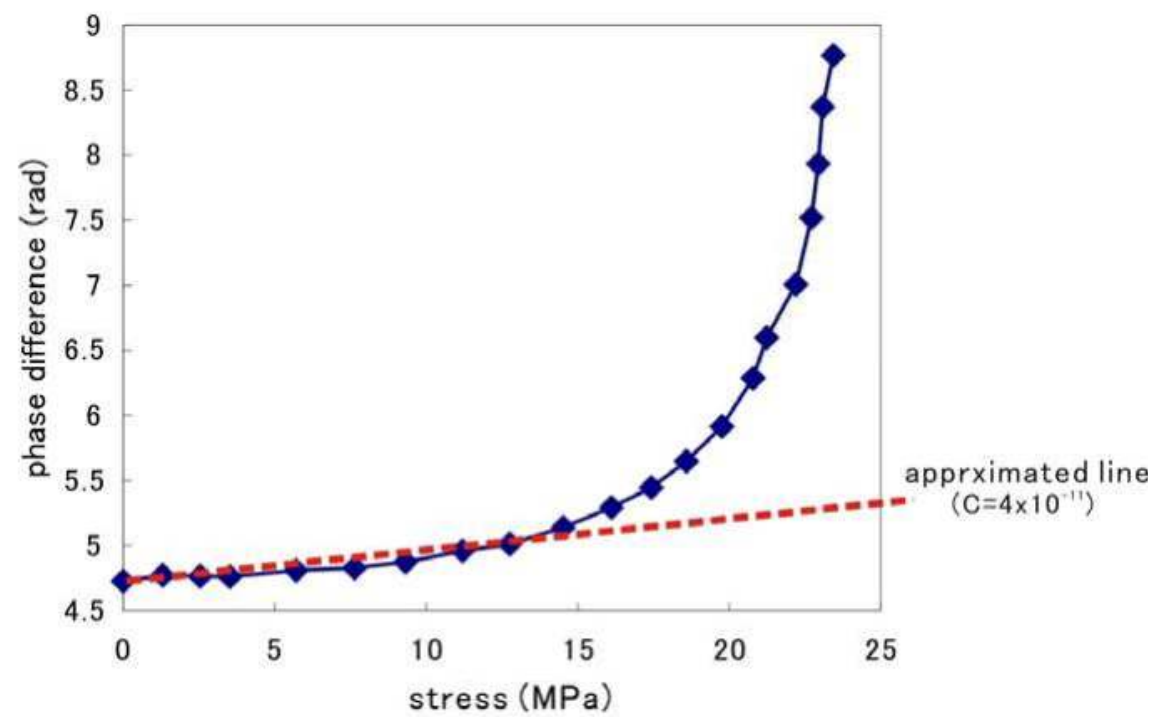

Fig. 13. Relationship between phase difference $\theta$ and applied mechanical stress 


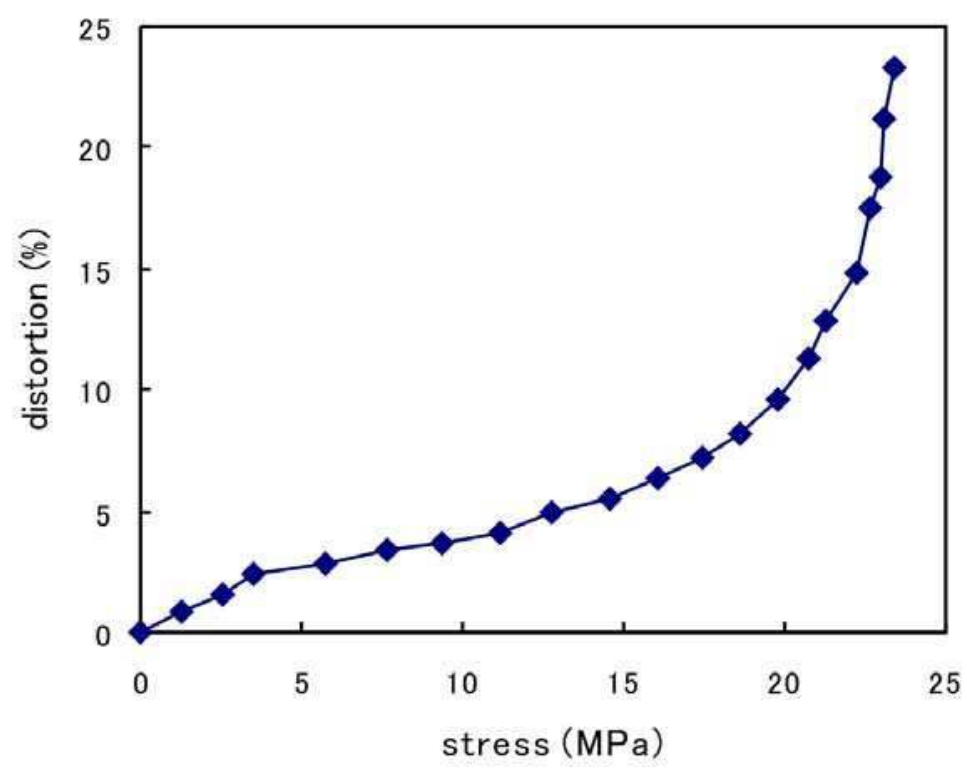

Fig. 14. Relationship between distortion of PE sample block and applied mechanical stress

\section{Conclusion}

$\mathrm{THz}$ wave technology is outstanding in recent optical engineering. Much development and application research is being carried out. In this chapter, one such research, the study of its application in the internal measurement of insulating materials, has been reviewed. Some measurements have been carried out with polyethylene, in which $\mathrm{THz}$ waves show high transmission probability, and the internal cavity interface and mechanical stress were detected. The applicability of such internal measurement in polyethylene was presented. A calibration (and estimation) method should be investigated for it.

Other internal problems, such as locally high electric field and temperature rise, are also expected to be detected by the same transmitting measurement of $\mathrm{THz}$ wave in the future. Moreover, surface (and near surface) conditions of materials are expected to be detected by the measurement of reflected $\mathrm{THz}$ wave.

\section{Acknowledgment}

The author would like to thank Prof. Hidaka and his laboratory members of the University of Tokyo for their instruction and collaboration.

\section{References}

[1] T. Takahashi et al., Application of Measurement Technique for Polyethylene with Mechanical Stress/a Cavity Interface using THz Wave, Trans. Of IEE Japan-A, Vol. 127-A, No. 10, pp. 593-598 (2007) [in Japanese] 
[2] T. Takahashi, T. Takahashi and T. Okamoto, 'Study on measurement technique for polyethylene by using $\mathrm{THz}$ beam --detection of vacant gap interface of mm order and mechanichal stress--', CRIEPI Report W03014 (2004) [in Japanese]

[3] M. Shibuya et al., Proposition of all solid insulated substation', CRIEPI Report W00047 (2000) (in Japanese)

[4] S. Matsuura et al., A compact terahertz radiation source for high-resolution spectroscopy, IEICE Technical Report, No. LQE97-5 (1997) [in Japanese]

[5] T. Taniuchi et al., Widely Tunable Terahertz Electromagnetic Radiation by Nonlinear Optical Effect, The Review of Laser Engineering (The Laser Society of Japan), Vol. 30, No. 7, pp. 365-369 (2002) [in Japanese]

[6] K. Kawase et al., Widely Tunable Coherent THz-Wave Generation Using Nonlinear Optical Effect, Trans. Of IEICE, Vol. J81-C-I, No. 2, pp. 66-73 (1998) [in Japanese]

[7] K. Kawase et al., "Injection-seeded terahertz-wave parametric generator with wide tenability", Appl. Phys. Lett., Vol. 80, No. 2, pp. 195-197 (2002)

[8] J. T. Darrow et al., Saturation Properties of Large-Aperture Photoconducting Antennas, IEEE J. Quantum Electron., 28, pp. 1607-1616 (1992)

[9] M. Hangyo et al., Terahertz Radiation from High-Temperature Superconductors, The Review of Laser Engineering (The Laser Society of Japan), Vol. 26, No. 7, pp. 536-540 (1998) [in Japanese]

[10] M. Tonouchi ,THz radiation from high-Tc superconductor, OYOBUTURI(JSAP), Vol. 66, No. 9, pp. 988-989 (1997) [in Japanese]

[11] X. -C. Zhang et al., Generation of femtosecond electromagnetic pulses from semiconductor surfaces, Appl. Phys. Lett., Vol. 56(11), pp. 1011-1013 (1990)

[12] X. -C. Zhang et al., Optoelectronic measurement of semiconductor surfaces and interfaces with femtosecond optics, J. Appl. Phys., Vol. 71(1), pp. 326-338 (1992)

[13] K. Sakai et al., Terahertz Electromagnetic Waves: Generation and Applications, The Review of Laser Engineering (The Laser Society of Japan), Vol. 26, No. 7, pp. 515-521 (1998)

[14] X. -C. Zhang et al., Influence of electric and magnetic fields on THz radiation, Appl. Phys. Lett., Vol. 62(20), pp. 2477-2479 (1993)

[15] H. Ohtake et at., Intense THz Radiation from Semiconductors in a Magnetic Field and Its ApplicationA33, The Review of Laser Engineering (The Laser Society of Japan), Vol. 30, No. 7, pp. 360-364 (2002) [in Japanese]

[16] K. Sakai et al., Terahertz optoelectronics, OYOBUTURI(JSAP), Vol. 70, No. 2, pp. 149155 (2001) [in Japanese]

[17] Optoelectronic Industry and Technology Development Association, Optoelectronics Technology Report (2007) [in Japanese]

[18] F. Maiwald et al., Design and performance of a $2.7 \mathrm{THz}$ waveguide tripler, Proc. of $12^{\text {th }}$ Int. Symp. on Space terahertz Technology, pp. 320-329 (2001)

[19] A. Volkov, Submillimeter BWO spectroscopy of solids, Int. J. Infrared Millim. Waves, Vol. 8, No. 1, pp. 55-61 (1987)

[20] S. Komiyama et al., Ultrahigh Sensitivity Detection of Terahertz Waves Using Quantum Dots, The Review of Laser Engineering (The Laser Society of Japan), Vol. 30, No. 7, pp. 385-390 (2002) [in Japanese] 
[21] S. Ariyoshi et al., Terahertz Imaging with a Superconducting Detector Array, IEICE Technical Report, Vol. 106, No. 403(ED2006 184-199), pp. 59-63 (2006) [in Japanese] 


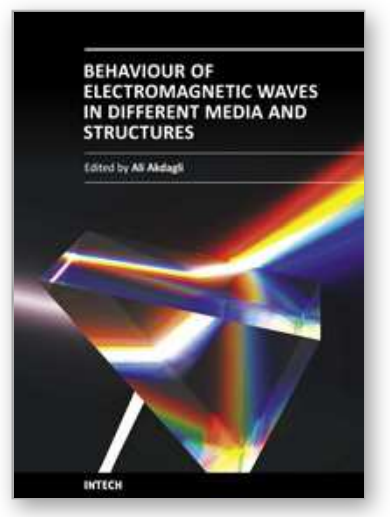

\section{Behaviour of Electromagnetic Waves in Different Media and Structures \\ Edited by Prof. Ali Akdagli}

ISBN 978-953-307-302-6

Hard cover, 440 pages

Publisher InTech

Published online 09, June, 2011

Published in print edition June, 2011

This comprehensive volume thoroughly covers wave propagation behaviors and computational techniques for electromagnetic waves in different complex media. The chapter authors describe powerful and sophisticated analytic and numerical methods to solve their specific electromagnetic problems for complex media and geometries as well. This book will be of interest to electromagnetics and microwave engineers, physicists and scientists.

\section{How to reference}

In order to correctly reference this scholarly work, feel free to copy and paste the following:

Tsuguhiro Takahashi (2011). Observation of Cavity Interface and Mechanical Stress in Opaque Material by THz Wave, Behaviour of Electromagnetic Waves in Different Media and Structures, Prof. Ali Akdagli (Ed.), ISBN: 978-953-307-302-6, InTech, Available from: http://www.intechopen.com/books/behavior-ofelectromagnetic-waves-in-different-media-and-structures/observation-of-cavity-interface-and-mechanicalstress-in-opaque-material-by-thz-wave 1

\section{INTECH}

open science | open minds

\section{InTech Europe}

University Campus STeP Ri

Slavka Krautzeka 83/A

51000 Rijeka, Croatia

Phone: +385 (51) 770447

Fax: +385 (51) 686166

www.intechopen.com

\section{InTech China}

Unit 405, Office Block, Hotel Equatorial Shanghai

No.65, Yan An Road (West), Shanghai, 200040, China

中国上海市延安西路 65 号上海国际贵都大饭店办公楼 405 单元

Phone: +86-21-62489820

Fax: +86-21-62489821 
(C) 2011 The Author(s). Licensee IntechOpen. This chapter is distributed under the terms of the Creative Commons Attribution-NonCommercialShareAlike-3.0 License, which permits use, distribution and reproduction for non-commercial purposes, provided the original is properly cited and derivative works building on this content are distributed under the same license. 